\title{
Anxiety and Depression Levels with Risk Factors of Breast Cancer \\ Patients in Erbil City - Iraq
}

Mosleh Saber Kareem; Department of Nursing, College of Nursing, Hawler Medical University, Erbil, Iraq.

(Correspondence: mosleh.kareem@hmu.edu.krd)

Diyar Hussain Taher; Department of psychiatry, College of Medicine, Hawler Medical University, Erbil, Iraq.

\section{ABSTRACT}

Background and objectives: Breast cancer appears to be becoming more common worldwide. It is the most common type of cancer in women in the Middle East and the Western countries. Patients with breast cancer are at a high risk of developing psychological problems such as anxiety and depression. This study aimed to evaluate the severity of anxiety and depression levels in breast cancer patients and their risk factors for breast cancer.

Methods: A quantitative descriptive study design was conducted at Rizgary Teaching Hospital and Nanakali Oncology Hospital in Erbil City in the Kurdistan Region of Iraq from 1st September 2020 to 5th August 2021. The duration of data collection was four months and purposive sampling was used to select 298 patients who were admitted to both hospitals. A questionnaire format was used to gather the data, and the Hospital Anxiety and Depression Scale (HADS) standardized questionnaire was utilized to measure the level of anxiety and depression.

Results: The average age of the patients was $45.28 \pm 9.17$ years, $80.5 \%$ were married, $60.7 \%$ of the studied sample had a low socio-economic status. Almost a third $(30.5 \%)$ of the participants had severe anxiety and $60.4 \%$ had severe depression. Concerning the risk factors of breast cancer, $82.2 \%$ of patients were obese, $91.9 \%$ did not do exercise, $35.6 \%$ had breast cancer family history, $93.6 \%$ were non-smoker, and $6.4 \%$ of them were smokers.

Conclusion: According to the findings, the majority of breast cancer patients suffer from anxiety and depression, and obesity is one of the risk factors for breast cancer.

Keywords: Anxiety; Depression; Breast cancer; Risk factors.

Received: 29/08/2021

Accepted: 14/ 11/2021

Published: 30/11/2021

\section{INTRODUCTION}

Breast cancer appears to be becoming more common around the world. It is the most common type of cancer in women in the Middle East and the West [1]. Urological $(21.3 \%)$, hematological $(18.0 \%)$, head and neck malignancies (15.0\%), and breast $(14.0 \%)$ cancer are the most prevalent cancer diagnoses [2].Globally, breast cancer is still the most frequent cancer among women and accounts for 14 to 42 percent of all female cancers in the Arab world. Its treatment can be a difficult experience for women, affecting their self-image and sexual relationships that can result in psychological reactions such as denial, rage, or acute dread toward their condition and treatment. Patients with breast cancer are at an increased risk of acquiring 
psychological problems such as depression and anxiety [3], and the treatment can cause patients a lot of sadness [4]. Breast cancer is one of the most researched oncological illnesses in terms of its impact on quality of life. The patients frequently experience high levels of anxiety and sadness, lowering their quality of life [5]. The diagnosis and treatment of this malignancy are well known for causing severe psychological suffering and discomfort, which is found to be present in more than $30 \%$ of cancer patients. Breast cancer patients have a high level of anguish following their diagnosis, which included sadness and anxiety. The amount of anxiety decreases over time. However, while anxiety and depression are both common in breast cancer patients, their effects on suffering differ. Anxiety, which is linked to a sense of uncertainty, appears to have a larger role in breast cancer patients' discomfort. Depression, on the other hand, which is characterized by negative emotions, does not correlate with the level of perceived distress in cancer patients. In contrast to depression, anxiety is frequently overlooked in the treatment of breast cancer patients' psychological well-being. Based on the current findings, a greater emphasis on assisting breast cancer patients in reducing their worry in the future is critical in lowering their perceived degree of discomfort [6]. Breast cancer patients may be uniquely susceptible to depression, anxiety, and resultant distress due to decreased estrogen levels secondary to hormone therapy and chemotherapy. It is important to routinely assess breast cancer sufferers for distress, and in collaboration with their primary care physicians, for signs and symptoms of insomnia, depression, anxiety, and distress. Counselling, mindful meditation and pharmacological interventions have helped many breast cancer survivors. The rate of depression in breast cancer patients $(4.5 \%-46 \%)$ is higher than rates in most other cancer types, also anxiety rates are (14.7\%) very high in people with breast cancer. During the first year following a diagnosis, patients are at the highest risk for major depressive disorder, especially for younger patients and those who have received chemotherapy. These high rates of depression may be due to a multi-factor including body image issues, physical effects of treatment, loss of sexual function, ongoing fatigue, and perpetual concern about recurrence. Anxiety rates are also very high in breast cancer patients. One large cohort study found pure anxiety symptoms in $14.7 \%$ [7]. According to the study done by Kameran et al. (2012) in Erbil city - Iraq, increased levels of melancholy and anxiety following a breast cancer diagnosis underscore the need for specialized psychiatric services [8].Breast cancer risk factors include both social and biological aspects including women's age, menarche at a young age, delayed first birth and menopause, nulliparity, short-term lactation, birth control pills, obesity, excessive fat consumption, hormone replacements Moreover, several epidemiological and clinical investigations have identified women with a family history of breast cancer as significant risk factors for the disease. On the other hand, the majority of breast cancer intervention literature suggests that modifiable risk factors can be avoided by promoting a healthy diet, regular physical activity, regulating alcohol consumption, and controlling weight, all of which are likely to reduce breast cancer incidence over time [9]. One study in South India discovered that urban regions have a higher incidence of breast cancer than rural ones. This study also found that the risk of breast cancer increased when the proportion of overweight or obese women in both premenopausal and post-menopausal women increased. The majority of breast cancer 
cases were found in women aged 40-49, who were mostly housewives. Breast cancer risk was shown to be 8 times greater among unmarried women, 3 times higher among nulliparous women, 2 times higher among postmenopausal women, and 10 times higher among those who never nursed. In comparison to married, nonnulliparous, premenopausal, women who breastfed, who have not been exposed to hormonal contraceptives, and women without any ovarian diseases, women who were exposed to hormonal contraceptives were 1.5 times more likely and women with ovarian diseases were 4.5 times more likely to be diagnosed with breast cancer [10].

\section{METHODS}

A quantitative descriptive study design was conducted at the Oncology Department of Rizgary Teaching Hospital and Nanakali Oncology Hospital in Erbil City in the Kurdistan region of Iraq from 1st September 2020 to 5th August 2021. The duration of data collection was four months, and 298 patients in both hospitals were selected as a purposive sample. A questionnaire format was modified and developed for the data collection. The sample selection was based on the following criteria: female breast cancer, undergoing treatments, new cases, no psychiatric diagnosis, ability to communicate verbally. The exclusion criteria included refusal of participation, metastasis, age (66 years and above). ). The data was gathered by the same researcher using an interview technique in the Kurdish language. Each patient's interview lasted 25-30 minutes and was divided into three parts: Part One included participants' sociodemographic characteristics, Part Two examined the breast cancer risk factors, and Part Three consisted of the Hospital Anxiety and Depression Scale (HADS) standardized questionnaire to measure the level of anxiety and depression. . HADS included 14 questions, 7 questions for anxiety and 7 questions for depression. Each question had 4 responses ranked from 0 to 3 , and the client selected one response that was appropriate to their situation. Normal scores ranged from 0 to 7, borderline abnormal scores ranged from 8 to 10 , and abnormal scores ranged from 11 to 21 [11]. The ethical permissions for performing this study came from the College of Nursing's ethical committee at Hawler Medical University. The goal of the study was described to the patients before their interview, and a verbal agreement was obtained. Patients were informed that they could withdraw from the study at any time. The data were entered into SPSS (version 23) for analysis, and the frequen$c y$, percentage, mean and standard deviation, t-test, and Chi-square test were used to analyze the data.

\section{RESULTS}

Table 1 shows that 41.6 percent of the participants were between the ages of 36 and 45. The participants' mean age (SD) was $45.28 \pm 9.17$. Regarding the educational level and occupation, most (29.5\%) of the studied sample graduated from an intermediate school and three quarters (74.8 $\%)$ of patients had unskilled manual occupations (housewives). The majority (80.5\%) of the study sample was married, more than half (60.7\%) had low economic status, and most (66.8\%) most lived in an urban area. Table 2 illustrates that almost a third of the women had a high level of anxiety (30.5\%) and most (64.4\%) of them suffered from high depression levels. Table 3 shows some of the risk factors of breast cancers. Concerning the age of the participants, less than half (41.6\%) were in the age group of $36-45$ years, the risk factors of breast cancer. The majority $(82.2 \%)$ of the women were obese. Concerning 
the daily exercise, the data showed that a high percentage $(91.9 \%)$ of participants did not do daily exercise. Less than half (35.6\%) of the study sample had a family history of breast cancer, while more than half (51.7\%) had a family history of other types of cancer. $86.2 \%$ of the study sample had menarche between 13-15 years of age, and more than half $(57.4 \%)$ were married at the age of $13-24$ years old. $84.2 \%$ of women had children, and $15.8 \%$ were childless.
Regarding the type of child's feeding, 75.8 $\%$ of the participants breastfed their children. Concerning contraceptive medication, $76.5 \%$ of them did not take any contraceptive medication. A high percentage (93.6\%) of the study sample was nonsmokers. Almost all (93.6\%) of respondents did not do breast self-examination, and $78.9 \%$ of them were diagnosed with breast cancer before the menopausal period.

Table1: Socio-demographic characteristics of patients $(n=298)$

\begin{tabular}{|c|c|c|c|}
\hline & Variables & No. & (\%) \\
\hline \multirow{4}{*}{ Age Group/years } & $26-35$ & 42 & (14.1) \\
\hline & $36-45$ & 124 & (41.6) \\
\hline & $46-55$ & 83 & $(27.9)$ \\
\hline & $56-65$ & 49 & (16.4) \\
\hline \multirow{7}{*}{ Educational level } & Primary school (or can read and write) & 87 & $(29.2)$ \\
\hline & Intermediate school & 88 & $(29.5)$ \\
\hline & High school or vocational & 44 & $(14.8)$ \\
\hline & Diploma (institute) & 15 & (5) \\
\hline & Bachelor degree (college) & 24 & (8.1) \\
\hline & Master degree or equivalent, e.g., higher diploma & 37 & (12.4) \\
\hline & PhD or equivalent & 3 & (1) \\
\hline \multirow{5}{*}{ Jobs } & Unskilled manual occupations & 223 & $(74.8)$ \\
\hline & Skilled manual and non-manual occupations & 29 & (9.7) \\
\hline & Associate professional occupations & 40 & $(13.4)$ \\
\hline & Skilled professional or senior managerial occupations & 6 & (2.1) \\
\hline & Married & 240 & $(80.5)$ \\
\hline \multirow{2}{*}{ Marital Status } & Single & 29 & (9.7) \\
\hline & Divorced & 8 & $(2.7)$ \\
\hline \multirow{4}{*}{ Socio-economic status } & Widow & 21 & (7.1) \\
\hline & Low & 181 & $(60.7)$ \\
\hline & Middle & 86 & (28.9) \\
\hline & High & 31 & $(10.4)$ \\
\hline \multirow{3}{*}{ Residency } & Urban & 199 & $(66.8)$ \\
\hline & Suburban & 63 & (21.1) \\
\hline & Rural & 36 & (12.1) \\
\hline
\end{tabular}


Table 2: Levels of anxiety and depression among breast cancer patients $(n=298)$

\begin{tabular}{lcccc}
\hline \multicolumn{1}{c}{ Levels } & Anxiety & \multicolumn{3}{c}{ Depression } \\
\hline & No. & (\%) & No. & (\%) \\
Normal & 137 & $(46)$ & 65 & $(21.8)$ \\
$\begin{array}{l}\text { Borderline Abnormal } \\
\text { (Borderline Case) }\end{array}$ & 70 & $(23.5)$ & 41 & $(13.8)$ \\
$\begin{array}{l}\text { Abnormal (Case) } \\
\quad \text { Total }\end{array}$ & 91 & $(30.5)$ & 192 & $(64.4)$ \\
& $\mathbf{2 9 8}$ & $\mathbf{( 1 0 0 )}$ & $\mathbf{2 9 8}$ & $\mathbf{( 1 0 0 )}$ \\
\hline
\end{tabular}

Table 3: Risk factors of breast cancer among 298 female breast cancers $(n=298)$

\begin{tabular}{|c|c|c|c|}
\hline Risk factors & & No. & $(\%)$ \\
\hline \multirow{3}{*}{ Ageing } & $26-35$ & 42 & $(14.1)$ \\
\hline & $36-45$ & 124 & $(41.6)$ \\
\hline & $46-55$ & 83 & $(27.9)$ \\
\hline \multirow[t]{2}{*}{ Mean \pm SD $=45.28 \pm 9.17$} & $56-65$ & 49 & $(16.4)$ \\
\hline & Underweight & 6 & $(2)$ \\
\hline \multirow[t]{2}{*}{ Body Mass Index } & Normal & 47 & $(15.8)$ \\
\hline & Obesity & 245 & $(82.2)$ \\
\hline \multirow{2}{*}{ Daily exercise before breast cancer } & Yes & 24 & (8.1) \\
\hline & No & 274 & $(91.9)$ \\
\hline \multirow{2}{*}{ Family history of breast cancer } & Yes & 106 & $(35.6)$ \\
\hline & No & 192 & $(64.4)$ \\
\hline \multirow{3}{*}{ Family history of all types of cancer } & Yes & 154 & (51.7) \\
\hline & No & 144 & $(48.3)$ \\
\hline & $10-12$ & 33 & $(11.1)$ \\
\hline \multirow[t]{3}{*}{ Menarche/ years } & $13-15$ & 257 & $(86.2)$ \\
\hline & $16-18$ & 8 & (2.7) \\
\hline & $13-24$ & 171 & $(57.4)$ \\
\hline \multirow{3}{*}{ Age of marriage/years } & $25-36$ & 84 & $(28.1)$ \\
\hline & 37 and above & 13 & (4.4) \\
\hline & Single & 30 & $(10.1)$ \\
\hline \multirow{2}{*}{ Do you have children } & Yes & 251 & $(84.2)$ \\
\hline & No (Infertility, Single) & 47 & $(15.8)$ \\
\hline \multirow{2}{*}{ Breastfeeding } & Yes & 226 & $(75.8)$ \\
\hline & No & 72 & $(24.2)$ \\
\hline \multirow{2}{*}{ Did you use contraceptive drugs? } & Yes & 70 & $(23.5)$ \\
\hline & No & 228 & $(76.5)$ \\
\hline \multirow[t]{2}{*}{ Smoking before breast cancer } & Yes & 19 & (6.4) \\
\hline & No & 279 & $(93.6)$ \\
\hline \multirow{2}{*}{ Breast self-examination } & Yes & 63 & $(21.1)$ \\
\hline & No & 235 & (78.9) \\
\hline \multirow{2}{*}{ Menopausal period } & Pre-menopause & 243 & (81.5) \\
\hline & Post-menopause & 55 & $(18.5)$ \\
\hline
\end{tabular}


Table 4 shows that there was a significant association between the levels of anxiety and risk factors of breast cancer such as menopause, sleep after diagnosis and cigarette smoking.
The same table shows that there were no statistically significant differences between anxiety levels and Body Mass Index, sleep before the diagnosis, exercise and breastfeeding.

Table 4: Association between risk factors of breast cancer and their levels of anxiety ( $n=298$ )

\begin{tabular}{|c|c|c|c|c|c|c|c|c|c|}
\hline \multicolumn{2}{|c|}{ Anxiety Levels and Risk factors } & \multicolumn{2}{|c|}{ Normal } & \multicolumn{2}{|c|}{$\begin{array}{c}\text { Borderline } \\
\text { Case }\end{array}$} & \multicolumn{2}{|c|}{ Case } & \multirow{2}{*}{ Total } & \multirow{2}{*}{$\begin{array}{c}\text { P- } \\
\text { value }\end{array}$} \\
\hline & & No. & (\%) & No. & (\%) & No. & (\%) & & \\
\hline \multirow{3}{*}{$\begin{array}{l}\text { Menopause } \\
\text { period }\end{array}$} & Pre-menopause & 102 & $(34.2)$ & 59 & (19.7) & 82 & $(27.5)$ & 243 & \multirow{2}{*}{0.009} \\
\hline & Post-menopause & 35 & $(11.7)$ & 11 & (3.6) & 9 & (3) & 55 & \\
\hline & $\begin{array}{l}\text { Underweight } \\
(\mathrm{BMI}<18.5)\end{array}$ & 3 & (1) & 1 & $(0.3)$ & 2 & $(0.6)$ & 6 & \multirow{5}{*}{0.231} \\
\hline \multirow{4}{*}{$\begin{array}{l}\text { Body Mass } \\
\text { Index }\end{array}$} & Normal & & & & & & & & \\
\hline & (BMI $\geq 18.5$ & 18 & (6) & 8 & $(2.7)$ & 21 & (7) & 47 & \\
\hline & and $<25$ ) & & & & & & & & \\
\hline & Obesity (BMI $\geq 25$ ) & 116 & (39) & 61 & (20.5) & 68 & $(22.8)$ & 245 & \\
\hline Sleep/Hour & $1-3$ hours & 13 & (4.3) & 13 & (4.3) & 13 & (4.3) & 39 & \multirow{3}{*}{0.065} \\
\hline before breast & 4- 6 hours & 20 & (6.7) & 14 & (4.7) & 23 & (7.7) & 57 & \\
\hline cancer & 7 and above & 104 & (34.9) & 43 & (14.4) & 55 & (18.4) & 202 & \\
\hline Sleep/Hour & $1-3$ hours & 12 & (4) & 6 & $(2)$ & 14 & (4.6) & 32 & \multirow{3}{*}{0.044} \\
\hline after breast & 4- 6 hours & 78 & $(26.1)$ & 47 & (15.7) & 61 & $(20.4)$ & 186 & \\
\hline cancer & 7 and above & 47 & $(15.7)$ & 17 & (5.7) & 16 & (5.3) & 80 & \\
\hline Smoking before & Yes & 7 & $(2.3)$ & 9 & (3) & 3 & (1) & 19 & \multirow{2}{*}{0.034} \\
\hline breast cancer & No & 130 & $(43.6)$ & 61 & (20.4) & 88 & (29.5) & 279 & \\
\hline Daily exercise & Yes & 13 & $(4.3)$ & 1 & $(0.3)$ & 10 & (3.3) & 24 & \multirow{3}{*}{0.061} \\
\hline before breast & No & 124 & $(41.6)$ & 69 & $(23.1)$ & 81 & $(27.1)$ & 274 & \\
\hline cancer & Total & 137 & (45.9) & 70 & $(23.6)$ & 91 & $(30.5)$ & 298 & \\
\hline \multirow{4}{*}{ Breast Feeding } & Yes & 107 & (35.9) & 55 & (18.4) & 64 & $(21.5)$ & 226 & \multirow{4}{*}{0.337} \\
\hline & No & 30 & (10.1) & 15 & (5) & 27 & (9) & 72 & \\
\hline & & & & & & & & & \\
\hline & Total & 137 & (45.9) & 70 & (23.6) & 91 & $(30.5)$ & 298 & \\
\hline
\end{tabular}


Table 5 shows that there were significant statistical associations between the levels of depression and risk factors of breast cancer such as menopause and sleep after diagnosis.
The same table shows that there were no statistically significant differences between depression levels and Body Mass Index, sleep before diagnosis, exercise and breastfeeding.

Table 5: Association between risk factors of breast cancer and their levels of depression $(n=298)$

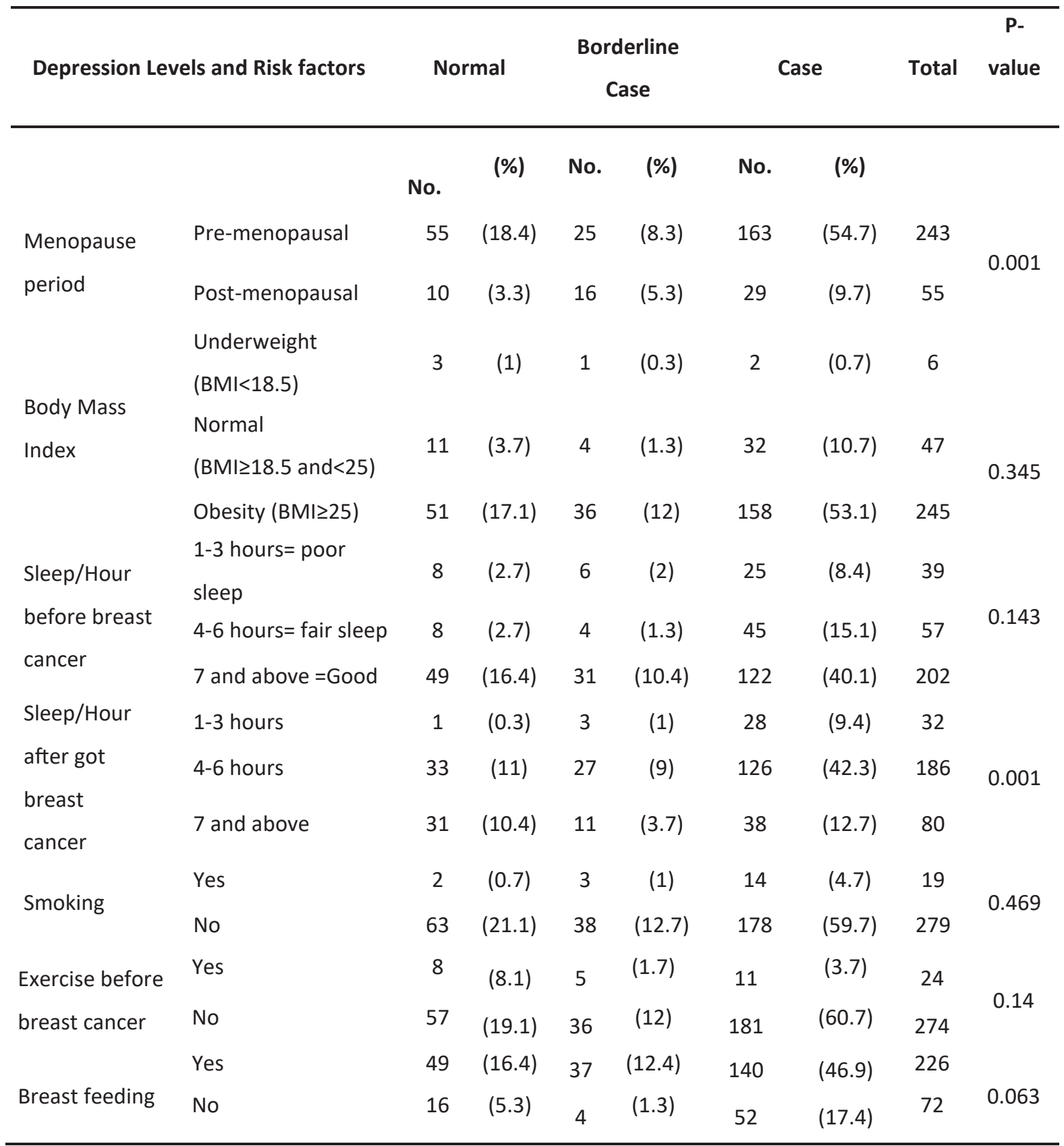




\section{DISCUSSION}

According to our knowledge, this is the first study to look at anxiety, depression, and breast cancer risk factors in breast cancer patients. Patients with breast cancer have a variety of symptoms related to the disease and its treatment and may have various psychological problems. In this study, anxiety and depression in breast cancer patients were chosen for examination. Regarding the age of the participants, less than half of the study sample was in the age group of 36-45 years. This is supported by the study done by Majid et .al (2009) and other researchers $[1,13,3,17]$. The majority of the participants in the study were married, which is consistent with the study done by Huang (2019) and others [12, 3, $17,18]$. According to the results of this study, the majority of the participants completed secondary school and lived in urban areas, which is compatible with the results of a study conducted by Tsaras, et al. (2018) $[3,17]$. The findings of the present study indicate that the majority of the respondents were married, housewives, had low socioeconomic status and were pre-menopausal. These results are compatible with the results of a study conducted in Egypt by Alagizy (2020) [17]. In this study, data on socioeconomic status were collected from breast cancer patients to investigate the relationship between economic position and anxiety and depression. The percentage of women who were anxious or depressed was directly related to their socioeconomic level and treatment costs. In addition, extra expenses were needed to buy the medications, because sometimes they were not available in hospitals. At that time, Iraq faced many problems such as; economic crisis and COVID -19. Regarding risk factors of breast cancer; the majority of the studied patients were obese. Weight gain before menopause and being overweight or obese after menopause are both linked to an increased risk of breast cancer $[1,18]$. Regarding breast self-examination, the majority of the participants did not do breast selfexamination monthly. These results are consistent with the study conducted in India in 2020 [10]. furthermore, the majority of studied patients were affected during the pre-menopausal period, which is in agreement with the study done by Chen et. al. in China [18]. The present study shows that less than half of the study sample had a family history of breast cancer and most of the study sample had a negative family history of breast cancer. These results are in concordance with the WHO (2021), which shows that breast cancer is more likely in families with a history of the disease, but the majority of women diagnosed with the disease have no known family history of the disease. The absence of a known family history does not always imply that a woman is at a lower risk. [14]. According to the data collected in this study, there were no statistically significant differences between anxiety levels and exercise, similar to the study by Sunil et al. (2012). Similarly, the combined data from 53 epidemiological studies showed no relationship between smoking and breast cancer [13]. The findings of this study revealed that anxiety and depression symptoms were common in studied breast cancer sufferers. Over half (60.4) percent of women had depression and 30.5 percent had anxiety symptoms based on HADS questionnaires. The prevalence of depression and anxiety in patients with breast cancer in our study was similar to the previous studies $[3,15]$. According to the findings of this study, there was no statistically significant relationship between the severity of depression and the 
socio-demographic characteristics of patients. These findings matched those of research conducted in Taiwan [16]. Furthermore, the present study revealed no significant difference between anxiety and depression levels and demographic characteristics of participants as in the research of Alagizy et al. [17]. The present study showed that there was a significant association between the levels of anxiety and risk factors of breast cancer such as menopause period, sleep after diagnosis and cigarette smoking. On the other side, there were no statistically significant differences between anxiety levels and Body Mass Index, sleep before diagnosis, exercise and breastfeeding. The present study results illustrated a significant association between the levels of depression and risk factors of breast cancer such as breast surgery, menopause period, sleep after diagnosis and having a child. Examining depression levels and Body Mass Index, sleep before diagnosis, exercise and breastfeeding revealed that there was no statistically significant association between them. The differences between this study's findings and other studies could be attributed to the questionnaire technique, sample size, culture, religion, ethnicity, and economic level.

\section{CONCLUSION}

According to the findings, the majority of the patients showed severe anxiety and depression symptoms. In general, there was no statistically significant relationship between anxiety and depression levels and socio-demographic factors; only the age group was statistically significant. There were significant differences between the anxiety and risk factors of breast cancer such as menopause period, sleep after diagnosis and cigarette smoking. . For the rest of the variables, there were no statistically significant differences between anxiety and Body Mass Index, sleep before diagnosis, exercise and breastfeeding. There were significant associations between depression and risk factors of breast cancer such as breast surgery, menopause period, sleep after diagnosis and having a child. The Body Mass Index, sleep before diagnosis, exercise and breastfeeding were not associated with depression levels. The study results indicate that the patients should be guided to psycho-education programs that can significantly reduce anxiety and depression. Furthermore, the availability of a psychiatric nurse or a clinical psychologist who can provide adequate psycho-oncological therapy to patients who are most likely to develop psychopathological issues would be very beneficial for cancer care in the region. They are currently not available but very much needed and recommended by the author of this research.

\section{CONFLICT OF INTERESTS}

The authors report no conflicts of interest and any sources of financial support.

\section{REFERENCES}

[1] Majid RA, Mohammed HA, Saeed HM, Safar BM, Rashid RM, Hughson MD. Breast cancer in Kurdish women of northern Iraq: incidence, clinical stage, and case-control analysis of parity and family risk. BMC women's health. 2009;9(1):1-6.

[2] Jadoon NA, Munir W, Shahzad MA, Choudhry ZS. Assessment of depression and anxiety in adult cancer outpatients: a crosssectional study. BMC Cancer. 2010;10(1):1-7.

[3] Tsaras K, Papathanasiou IV, Mitsi D, Veneti A, Kelesi M, Zyga S, et al. Assessment of depression and anxiety in breast cancer patients: prevalence and associated factors. Asian Pacific journal of cancer prevention. 2018;19(6):1661.

[4] Akel R, El Darsa H, Anouti B, Mukherji D, Temraz S, Raslan R, et al. Anxiety, 
depression and quality of life in breast cancer patients in the Levant. Asian Pacific journal of cancer prevention: 2017;18 (10):2809.

[5] Bellver-Perez A, Peris-Juan C, SantaballaBeltrán A. Effectiveness of therapy group in women with localized breast cancer. International Journal of Clinical and Health Psychology. 2019;19(2):107-14.

[6] Ng CG, Mohamed S, Kaur K, Sulaiman AH, Zainal NZ, Taib NA, et al. Perceived distress and its association with depression and anxiety in breast cancer patients. PLOS One. 2017;12(3):e0172975.

[7] Tkaczuk KH, Kesmodel SB, Feigenberg SJ. Handbook of breast cancer and related breast disease: Springer Publishing Company; 2016.

[8] Ismail KH, Tahir DH, Barzinji BK. Depression and anxiety in women with breast cancer in Erbil city: a case-control study. Zanco Journal of Medical Sciences. 2012;16(1):65- 70

[9] ] Prusty RK, Begum S, Patil A, Naik D, Pimple S, Mishra G. Knowledge of symptoms and risk factors of breast cancer among women: a community-based study in a low socio-economic area of Mumbai, India. BMC women's health. 2020; 20:1-12.

[10] Ranjan Kumar Prusty, Shahina Begum, Anushree Patil, DD. Naik, Sharmila Pimple and Gaurav Mishra. Knowledge of symptoms and risk factors of breast cancer among women: a community-based study in a low socio-economic area of Mumbai, India. BMC Women's Health (2020) 20:106.P.12.https://

bmcwomenshealth.biomedcentral.com.

[11] Yasin YM, Al-Hamad A. Anxiety and depression as key determinants of cancerrelated fatigue among patients receiving chemotherapy. European Scientific Journal. 2015;11(33).

[12] Hsiu-Mei Huang, Jun-Hung Lai, Tsai-Wei Huang. Mediating effects of depression on anxiety and leisure constraints in patients with breast cancer. BMC Women's Health. 2019Nov20;19(1):141.https:// bmcwomenshealth.biomedcentral.com.

[13] Sunil R, Lakhani Ian O. Ellis Stuart J. Schnitt Puay Hoon Tan Marc J. van de Vijver. WHO Classification of Tumours of the Breast, 4th edition. International Agency for Research on Cancer. Lyon, 2012. P.17.
[14] WHO. Breast cancer, 2021. https:// www.who.int/news-room/fact-sheets/ detail/breast-cancer.

[15] Civilotti C, Botto R, Maran DA, Leonardis BD, Bianciotto B, Stanizzo MR. Anxiety and Depression in Women Newly Diagnosed with Breast Cancer and Waiting for Surgery: Prevalence and Associations with SocioDemographic Variables. Medicina Journalscientific journal of the Lithuanian University of Health Sciences 2021;57(5):454. https:// www.mdpi.com/1648-9144/57/5/454.

[16] Su J-A, Yeh D-C, Chang C-C, Lin T-C, Lai C-H, $\mathrm{Hu} P-\mathrm{Y}$, et al. Depression and family support in breast cancer patients. Neuropsychiatric disease and treatment. 2017; 13:2389.

[17] Alagizy H, Soltan M, Soliman S, Hegazy N, Gohar S. Anxiety, depression and perceived stress among breast cancer patients: single institute experience. Middle East Current Psychiatry. 2020;27(1):1-10.

[18] Chen X, Zheng Y, Zheng W, Gu K, Chen Z, Lu $W$, et al. Prevalence of depression and its related factors among Chinese women with breast cancer. ACTA Oncologica Journal. 2009;48(8):1128-36.

[19] Wali Omer, Tariq Al-Hadithi. Developing a socio-economic index for health research in Iraq. Eastern Mediterranean Health Journal. Vol.23No.10,https:// pubmed.ncbi.nlm.nih.gov/29270967. 